\title{
Functional alterations of mesenteric small resistance arteries in Milan hypertensive and normotensive rats
}

\author{
Damiano Rizzoni ${ }^{1}$, Maurizio Castellano ${ }^{1}$, Enzo Porteri ${ }^{1}$, Mara Giacchè ${ }^{1}$, Patrizia Ferrari ${ }^{2}$, Daniele Cusi ${ }^{3}$, \\ Carolina De Ciuceis ${ }^{1}$, Gianluca EM Boari ${ }^{1}$ and Enrico Agabiti Rosei ${ }^{1}$
}

The Milan hypertensive rat strain (MHS) is a genetic strain in which cardiovascular phenotypes seem to be dependent, at least in part, on adducin gene polymorphisms. The aim of our study was to evaluate the structure, contractile responses and endothelium-dependent vasodilation in mesenteric small resistance arteries in 12-week-old MHS, ( $n=7)$, age-matched Milan normotensive rats (MNS, $n=7$ ) and congenic strains in which the DNA segments carrying the $\alpha$-adducin locus from the MHS have been introgressed into the MNS (MNA, $n=7$ ). Systolic blood pressure (tail cuff) and left ventricular weight to body weight were measured. Mesenteric small arteries were dissected and mounted on a micromyograph; the media:lumen ratio was then calculated. Concentration-response curves to acetylcholine and to norepinephrine (NE) were created. Systolic blood pressure was significantly increased in the MHS and MNA strains compared with the MNS. No significant difference in mesenteric small resistance artery structure was observed among the groups; however, a slightly more elevated media:Iumen ratio was observed in MNA compared with the MNS. In contrast, left ventricular weight to body weight was significantly increased and ACH-induced dilatation was significantly impaired in the MHS and in MNA compared with MNS. The concentration-response curve to NE in the MHS showed significantly reduced sensitivity to NE; however, maximum contraction was increased in the MHS vs. the other groups. The MHS presents cardiac (but not vascular) remodeling, endothelial dysfunction and a peculiar contractile response to $\mathrm{NE}$, compared with the other groups. The systolic blood pressure increase and trend to vascular remodeling in MNA support the pathogenic role of $\alpha$-adducin.

Hypertension Research (2009) 32, 581-585; doi:10.1038/hr.2009.57; published online 1 May 2009

Keywords: acetylcholine; adducin; microcirculation; norepinephrine; remodeling; small arteries

\section{INTRODUCTION}

Adducin is a heterodimeric cytoskeleton protein consisting of an $\alpha$-subunit and either a $\beta$ - or $\gamma$-subunit. ${ }^{1}$ In rats and humans, the mutation of the $\alpha$-adducin subunit leads to the stimulation of the sodium $\left(\mathrm{Na}^{+}\right)$and potassium $\left(\mathrm{K}^{+}\right)$-adenosine triphosphatase (ATPase) activity in renal tubular cells, thus inducing increased renal sodium reabsorption, and, subsequently, hypertension, ${ }^{1}$ although other mechanisms may also be involved in the increase of blood pressure values associated with the mutations of the adducin gene. Experimental, clinical and epidemiological evidence suggests that some pathogenetic mechanisms may lead to hypertension associated with the $\alpha$-adducin Gly460Trp polymorphism. ${ }^{1,2}$ We could show earlier the presence, in a general population, of a relationship of this genetic polymorphism of $\alpha$-adducin with blood pressure values. ${ }^{3}$ In fact, there was an association between Trp460 allele and hypertension, with a relative risk for patients carrying at least one Trp460 allele of $\sim 1.6^{3}$

However, the data about relationships between genetic polymorphism of $\alpha$-adducin gene and vascular damage or dysfunction are less clear. No association was found between Gly460Trp polymorphism and the intima media thickness of the carotid arteries in a general population. ${ }^{3}$ However, the $460 \operatorname{Trp}$ allele contributed substantially to the increased carotid intima media thickness in young, adult males. ${ }^{4}$ In a study by Balkenstein et al.,5,6 a relationship was observed between the intima media thickness of the large muscular femoral artery and the ACE gene. This relationship is only seen in the presence of the $\alpha$-adducin $460 \operatorname{Trp}$ allele, thus suggesting the presence of an epistatic interaction. The discrepancies between different studies may be explained by the different characteristics of the populations examined and by the limitation inherent in the candidate-gene approach. ${ }^{7}$ Even fewer data are presently available about the effect of the adducin gene polymorphisms on vascular endothelial function. Recently, an association between endothelium-dependent dilatation in the forearm and the $460 \mathrm{Trp}$ allele was observed in a population of essential hypertensives. ${ }^{8}$

The Milan hypertensive rat strain (MHS), and its normotensive counterpart (MNS) are a good animal model for studying the role of adducin in the development of hypertension. ${ }^{1,2}$ In an analogy with the human situation, transplantation of a kidney from an MNS donor to

${ }^{1}$ Clinica Medica, Department of Medical and Surgical Sciences, University of Brescia, Brescia, Italy; ${ }^{2}$ Prassis Sigma Tau Research Institute, Milan, Italy and ${ }^{3}$ Filarete Foundation \& Chair of Nephrology, University of Milan, Milan, Italy

Correspondence: Professor D Rizzoni, Department of Medical and Surgical Sciences, University of Brescia, c/o 2a Medicina, Spedali Civili, 25100 Brescia, Italy. E-mail: rizzoni@med.unibs.it

Received 31 October 2008; revised 31 March 2009; accepted 1 April 2009; published online 1 May 2009 
an MHS recipient, reduced blood pressure (and increased sodium excretion) and vice versa. ${ }^{1}$ Genetic crosses showed that the MHS Add1 variant co-segregated with a significant increase in blood pressure in the MNS $\times$ MHS F2 generation. ${ }^{1}$ A whole-genome scan in the F2 population showed a quantitative trait locus containing the Add1 locus, ${ }^{1}$ thus suggesting that the mechanism underlying the development of hypertension in such a strain is related to an altered adducin function. ${ }^{2}$ However, in this model of genetic hypertension no data are available regarding the role of the adducin gene in the development of microvascular structural and functional abnormalities. Therefore, we considered it worthwhile to evaluate the structure, contractile responses and endothelium-dependent vasodilation in mesenteric small resistance arteries of MHS, $(n=7)$, of age-matched MNS and of a congenic strain in which the DNA segments carrying the $\alpha$-adducin locus from the MHS have been introgressed into the MNS.

\section{METHODS}

We studied seven male MHS rats at 12 weeks of age, seven age-matched MNS rats and a congenic strain in which the DNA segments carrying the $\alpha$-adducin locus from the MHS rats have been introgressed into the MNS (MNA, $n=7$ ). The animals were obtained from Prassis Sigma Tau Research Institute, Milan, Italy. Details about gene transfer in reciprocal congenic strains of Milan rats have been published earlier. ${ }^{9}$

All the procedures followed were in accordance with the guidelines of our institution (Medical School, University of Brescia). The rats were housed two to a cage in a room in which the temperature was controlled between 23 and $25^{\circ} \mathrm{C}$, and a 12-h light/dark cycle was maintained. Food and water were supplied ad libitum. Systolic blood pressure values and heart rate were measured non-invasively (tail cuff method, IITC Life Science Instruments, Woodland Hills, CA, USA) in conscious rats every week.

On the day of death, the animals were weighed and then killed by decapitation. The heart was promptly dissected, dried and weighed, and the heart weight, left ventricular weight, heart weight/body weight and left ventricular weight to body weight (relative left ventricular mass) were calculated. At the same time, from each rat, mesenteric vessels corresponding to the second branch (about $140-200 \mu \mathrm{m}$ of average diameter in relaxed conditions, $2 \mathrm{~mm}$ long) were obtained by dissection. The vessel segments were excised free of connective and adipose tissue and two stainless steel wires of $40 \mu \mathrm{m}$ in diameter were threaded through the lumen. This ring preparation was mounted on a micromyograph, as described earlier by Mulvany et al. ${ }^{10,11}$ The vessels were then equilibrated and relaxed for at least $30 \mathrm{~min}$ in a physiological saline solution. The physiological saline solution had the following composition: $\mathrm{MgSO}_{4} 1.17, \mathrm{CaCl}_{2} 2.5$ and glucose 5.5, which was kept constantly at $37^{\circ} \mathrm{C}$ and bubbled with $5 \% \mathrm{CO}_{2}$ in oxygen.

After equilibration, the micromyograph was transferred to the stage of a light microscope with an immersion lens. The following parameters were measured: wall thickness, media thickness, internal diameter, media to lumen ratio. For further details, see Rizzoni et al. ${ }^{12-14}$ and Vecchione et al. ${ }^{15}$

The functional characteristics of the vessels were then evaluated. The vessels were exposed three times to PSS with equimolar exchange of $\mathrm{NaCl}$ for $\mathrm{KC} 1$ (KPSS) (2 min, with a 10-min interval) to evaluate their response to potassium, the maximal response usually being observed during the third stimulation.

Each vessel was then stimulated as follows:

- a cumulative concentration-response curve to $\mathrm{NE}$ at the following concentrations: $0.01,0.05,0.1,0.5,1,5,10 \mu \mathrm{moll}^{-1}, 3 \mathrm{~min}$ per concentration. As the contraction of the vessel with the highest concentration of NE was similar to that evoked by KPSS, at least in our experimental conditions, our concentration-response curve to NE explored almost all of the range of contraction of our vessels.

- a cumulative dose-response curve to endothelin-1 at the following concentrations: $0.0001,0.001,0.01,0.1 \mu \mathrm{moll}^{-1}, 3 \mathrm{~min}$ per concentration.

- a cumulative concentration-response curve to acetylcholine at the following concentrations: $0.001,0.01,0.1,1,10 \mu \mathrm{moll}^{-1}, 3 \mathrm{~min}$ per concentration, after precontraction with NE $10 \mu \mathrm{moll}^{-1}$.
- a cumulative concentration-response curve to sodium nitroprusside at the following concentrations: $0.001,0.01,0.1,1,10 \mu \mathrm{moll}^{-1}, 3$ min per concentration, after precontraction with $\mathrm{NE} 10 \mu \mathrm{moll}^{-1}$. The response to acetylcholine or sodium nitroprusside was expressed as the percentage decrease of the wall tension obtained with NE precontraction.

The response to each concentration was measured as the active force at the end of each $3 \mathrm{~min}$ period. Wall tension (active force divided by two times the segment length) and active media stress (wall tension divided by media thickness) were then calculated. ${ }^{12-14}$ If the vessels produced rhythmic activity, the response was measured from the mean active force for the last $20 \mathrm{~s}$ of each period.

For further details about the methods used, see Rizzoni et al. ${ }^{12,13}$ Morphological and functional results from two different blood vessels in each rat were averaged to provide one mean observation per subject. Data were analyzed in a blind manner.

\section{Statistical analysis}

All data are expressed as mean \pm s.d., unless otherwise stated. One-way ANOVA (analysis of variance) was used to evaluate the differences among the groups. Two-way ANOVA for repeated measures was used the evaluation of the concentration-response curves (group $\times$ concentration) (BMDP Statistical Software programs 7D, 1 and 2 V, BMDP Statistical Software Inc., Los Angeles, CA, USA).

The statistical significance was set at the conventional level of 5\%.

\section{RESULTS}

\section{Blood pressure and vascular structure}

Systolic blood pressure was significantly higher in the MHS and the MNA strains than in the MNS (Table 1). No significant difference in the mesenteric small resistance artery structure, as expressed by the measurement of the tunica media-to-lumen ratio, was observed between MHS and MNS; although the media-to-lumen ratio and media thickness were slightly larger in the MNA than in the MNS (Table 1). No significant difference was observed for the internal diameter or the wall thickness.

\section{Cardiac structure}

Body weight and heart weight, left ventricular weight, heart weight/ body weight and left ventricular weight to body weight were significantly larger in the MHS than in the MNS (Table 1).

No significant difference in cardiac morphology was observed between the MNA and the MNS (Table 1), whereas all morphological parameters remained significantly smaller in the MNA than in the MHS. Therefore, despite the significant blood pressure increase, the congenic strain did not develop cardiac structural alterations.

\section{Vascular function}

Acetylcholine-induced dilatation was significantly impaired in the MHS and the MNA strain, compared with the MNS (Table 2, Figure 1). No difference among groups was observed in the endothelium-independent vasodilation to sodium nitroprusside (Table 2, Figure 2).

The concentration-response curve to NE in the MHS showed a significantly reduced sensitivity to NE ( $\log \mathrm{EC}_{50}$ : MNS: $-6.33 \pm 0.37$; MHS: $-5.29 \pm 0.67, P<0.01)$; however, maximum contraction was increased in the MHS vs. the other groups (Table 2, Figure 3).

No difference in the concentration response to endothelin-1 was observed among the groups (Table 2, Figure 4).

\section{DISCUSSION}

Milan hypertensive rat strain is a genetic strain in which the cardiovascular phenotypes seems to be dependent, at least in part, from 
Table 1 Blood pressure, body weight and cardiac or microvascular morphological parameters in the different groups of rats

\begin{tabular}{|c|c|c|c|c|c|c|c|c|c|c|c|}
\hline & $\begin{array}{l}\text { Systolic } \\
\text { blood } \\
\text { pressure } \\
(\mathrm{mm} \mathrm{Hg})\end{array}$ & $\begin{array}{l}\text { Heart rate } \\
\text { (beats/min) }\end{array}$ & $\begin{array}{c}\text { Body } \\
\text { weight } \\
\text { (g) }\end{array}$ & $\begin{array}{c}\text { Heart } \\
\text { weight } \\
\text { (g) }\end{array}$ & $\begin{array}{c}\text { Left } \\
\text { ventricular } \\
\text { weight }(g)\end{array}$ & $\begin{array}{c}\text { Heart weight/ } \\
\text { body weight }\end{array}$ & $\begin{array}{c}\text { Left } \\
\text { ventricular } \\
\text { weight/Body } \\
\text { weight }\end{array}$ & $\begin{array}{l}\text { Media-to-lumen } \\
\text { ratio }\end{array}$ & $\begin{array}{c}\text { Wall } \\
\text { thickness } \\
(\mu \mathrm{m})\end{array}$ & $\begin{array}{c}\text { Media } \\
\text { thickness } \\
(\mu \mathrm{m})\end{array}$ & $\begin{array}{c}\text { Internal } \\
\text { diameter } \\
(\mu \mathrm{m})\end{array}$ \\
\hline MNS $(n=7)$ & $139 \pm 1.7$ & $289 \pm 38$ & $379 \pm 22$ & $0.98 \pm 0.04$ & $0.63 \pm 0.03$ & $2.60 \pm 0.08$ & $1.67 \pm 0.09$ & $0.106 \pm 0.012$ & $39.4 \pm 5.42$ & $22.1 \pm 2.48$ & $3213 \pm 34$ \\
\hline MHS $(n=7)$ & $167 \pm 1.8^{* * *}$ & $322 \pm 45$ & $411 \pm 29 *$ & $1.24 \pm 0.07^{* * *}$ & ${ }^{*} 0.82 \pm 0.08^{* * *}$ & $3.01 \pm 0.10^{* * *}$ & ${ }^{*} 1.98 \pm 0.10^{* * *}$ & $0.101 \pm 0.011$ & $42.1 \pm 2.38$ & $22.6 \pm 1.38$ & $3230 \pm 36$ \\
\hline MNA $(n=7)$ & $156 \pm 1.9^{* *}$ & $316 \pm 36$ & $397 \pm 32$ & $1.05 \pm 0.08^{\# \# \#}$ & $0.67 \pm 0.06 \# \#$ & $2.64 \pm 0.19^{\# \#}$ & $1.70 \pm 0.16^{\# \#}$ & $0.116 \pm 0.005^{\# \# *}$ & $44.3 \pm 4.09$ & $25.2 \pm 2^{* \#}$ & $220 \pm 23$ \\
\hline
\end{tabular}

Table 2 Functional responses in mesenteric small resistance arteries of MHS, MNS and MNA

\begin{tabular}{lccc}
\hline & $\begin{array}{c}\text { Acetylcholine } \\
\text { (\% reduction of wall tension) }\end{array}$ & $\begin{array}{c}\text { Sodium nitroprusside } \\
\text { (\% reduction of wall tension) }\end{array}$ & $\begin{array}{c}\text { Norepinephrine } \\
10 \mu \mathrm{mol}^{-1}(\mathrm{KPa})\end{array}$ \\
\hline MNS $(n=7)$ & $-79 \pm 8.69$ & $-47 \pm 9.07$ & $113 \pm 18.9$ \\
MHS $(n=7)$ & $-25 \pm 8.69^{* * *}$ & $-62 \pm 4.54$ & $175 \pm 27.2^{*}$ \\
MNA $(n=7)$ & $-62 \pm 9.83^{\#}$ & $-44 \pm 5.29$ & $128 \pm 18.1^{\#}$ \\
\hline
\end{tabular}

${ }^{*} P<0.05,{ }^{* * *} P<0.001$ vs. MNS; ${ }^{\#} P<0.05$ vs. M.

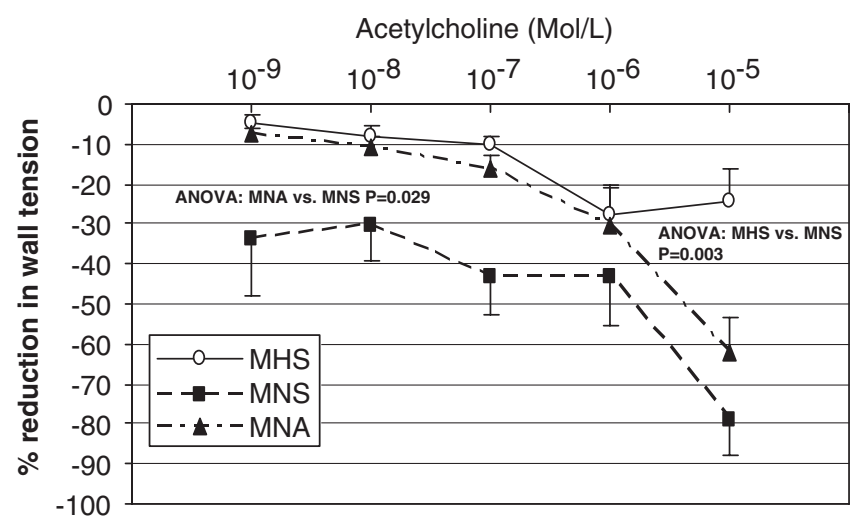

Figure 1 Concentration-response curve to acetylcholine in the different groups of rats. ANOVA; MHS vs. MNS: $P=0.003$, MHS vs. MNA: $P=N S$, MNA vs. MNS: $P=0.029$. $n=7$ in each group.

\section{Sodium nitroprusside (Mol/L)}

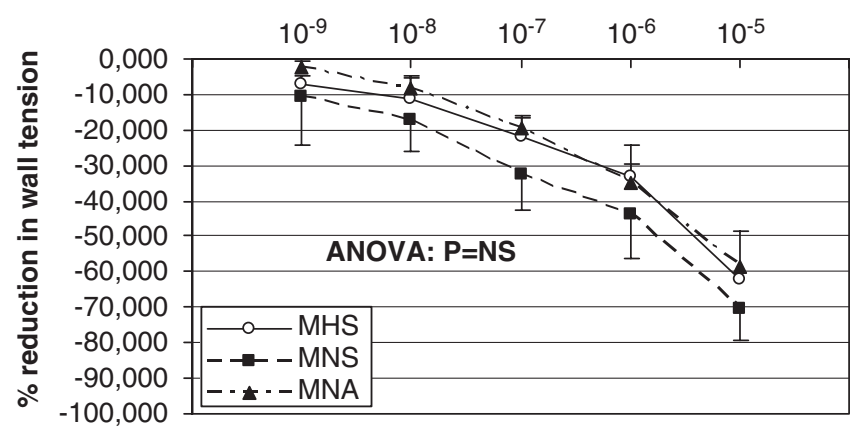

Figure 2 Concentration-response curve to sodium nitroprusside in the different groups of rats. ANOVA: $P=$ NS among groups. $n=7$ in each group.

adducin gene variability. ${ }^{1,2}$ Morphological and functional cardiovascular alterations, including an enhanced myogenic tone in the vasculature and organ hypertrophy were observed in association

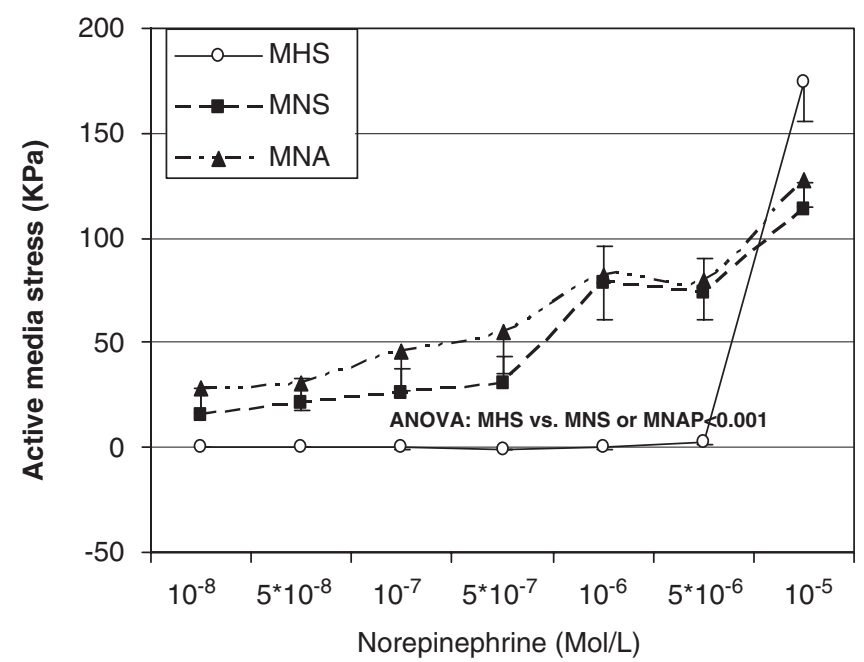

Figure 3 Concentration-response curve to norepinephrine in the different groups of rats. ANOVA $P<0.001$ between MHS and all the remaining groups. $n=7$ in each group.

with mutated adducin; ${ }^{16}$ however, very few investigations have specifically addressed the microvascular and cardiac structural alterations in the MHS.

In this study, cardiac hypertrophy is clearly present in the MHS, being possibly a consequence of elevated blood pressure levels or of specific alterations at the cellular levels, namely in the transcellular exchange of ions or changes in the structure of specific cellular proteins. ${ }^{16-18}$ The observed finding cannot be interpreted as mainly dependent on the effects of $\alpha$-adducin, as the congenic strain does not present the same cardiac structural changes despite similar blood pressure increase. It seems therefore that the genetic background of the MHS and the MNS interacts differently with mutated adducin in terms of blood pressure increase and left ventricular hypertrophy development.

It was proposed that adducin genes may be involved in the atherosclerotic alterations observed in medium-large vessels. ${ }^{19,20}$ 


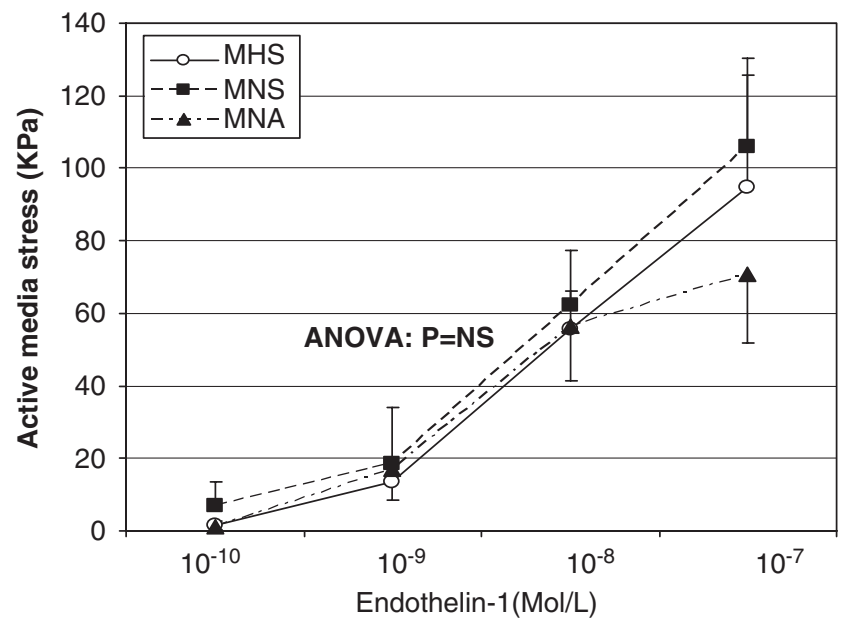

Figure 4 Concentration-response curve to endothelin- 1 in the different groups of rats. No significant difference among groups. $n=7$ in each group.

The mechanisms involved include increased susceptibility of adducin to phosphorylation by $\rho$-kinase in the coronary lesions, ${ }^{20}$ or a change in the balance among proliferative factors, apoptosis-related molecules and relaxant anti-proliferative receptors in the MHS carotids, with consequent stenosis progression. ${ }^{19}$

Established hypertension is usually associated with the presence of structural alterations in small resistance arteries. ${ }^{21}$ These alterations are characterized by an increase in the thickness of the tunica media layers and by a reduction in the internal diameter. As a consequence, the media-to-lumen ratio increases. The increase in the media-tolumen ratio may be ascribed to hypertrophy or hyperplasia of vascular smooth muscle cells (hypertrophic remodeling) or to a re-arrangement of the same material around a narrowed lumen (eutrophic remodeling) ${ }^{22}$ Regardless of the mechanism involved in their onset, vascular structural alterations may play an important role in the development and/or maintenance of hypertension. ${ }^{21,23}$

Only one study has earlier used the same micromyographic method employed in this study for the assessment of small resistance artery structure in the MHS. ${ }^{24}$ In this study, however, no comparison between the MHS and the MNS was performed. The authors observed a modest effect of the ACE inhibitor, perindopril, administered for 20 weeks at high doses on the mesenteric small resistance artery structure, with no persistent effect on blood pressure after treatment withdrawal, at variance with earlier observations in a different rat strain, the spontaneously hypertensive rat. ${ }^{13,25}$ In Mulvany's study, ${ }^{24}$ perindopril at low doses was ineffective on the vascular structure of the MHS, again in contrast with what was observed in spontaneously hypertensive rats. ${ }^{26}$ The authors concluded that the vascular structural changes in spontaneously hypertensive rats are, at least in part, dependent on the activation of the rennin-angiotensin system, whereas in the MHS, other mechanisms, not influencing the microvascular structure, are involved. The results of this study support such a view, as no major difference in the mesenteric small resistance artery structure was observed between the MHS and the MNS, although a small increase in the media-to-lumen ratio and media thickness was observed in the MNA strain. It seems possible that the factors involved in the development of cardiac hypertrophy and microvascular remodeling may be partly different, with different relative contributions of growth factors, afterload, wall stress and integrins/extracellular matrix component. $^{27,28}$
A relevant interesting finding of this study is represented by the observation of an altered endothelium-dependent relaxation in the small arteries of the MHS. As mentioned earlier, a possible role of $\alpha$-adducin polymorphisms in the development of endothelial dysfunction was postulated in a population of essential hypertensives. ${ }^{8}$ The mechanisms involved are still unclear, although it was hypothesized earlier that oxidative stress may be increased in the essential hypertensives carrying the $460 \mathrm{Trp}$ allele of Add $1 .^{29}$ Other mechanisms possibly involved are related to effects of the mutated adducin on the density of integrins and adhesion molecules on the cell surface. ${ }^{30}$ Adducin may then exert a pleiotropic effect, both on the development of hypertension and on organ damage, as an endothelial dysfunction, through its effect on adhesion molecules, caused by a constitutive change in their cell-surface expression and by altering intracellular signals. $^{8}$

A second interesting finding of this study is the observation of quantitative and qualitative changes in the pattern of contractile response to NE in mesenteric small arteries of the MHS. It was shown earlier that, in adducin-dependent hypertension, alterations in the vascular $\mathrm{Na}+\mathrm{K}+$-ATPase are present and may be responsible for an increased vascular contractility. ${ }^{17}$ In addition, changes in caveolin-1 induced adducin phosphorylation may also play a role in this regard. ${ }^{18}$ In a cell-free system, rat-mutant adducin accelerates actin polymerization, ${ }^{2,31}$ thus possibly enhancing the effect of any contractile stimulus. However, when we compared the contractile response to endothelin-1, no difference between the groups was observed, thus suggesting that the observed pattern is, at least in part, specific for NE. In any case, further studies are needed to precisely elucidate the underlying mechanisms in the observed enhanced contractile response to NE in the MHS. In the MNA strain an increase in blood pressure values and of the media-to-lumen ratio of small arteries, compared with the MNS was observed, thus suggesting a partial role of $\alpha$-adducin, at least in this regard. Therefore, this study presents some evidence that the genetic background of the MHS prevents the development of vascular (but not cardiac) remodeling. Heterogeneity of regulatory mechanisms of the development of cardiac vs. vascular remodeling may be involved in the observed findings.

Possible limitations of the study are the lack of data about fibrosis and remodeling of the intramyocardial arteries, about left ventricular geometry or about large artery morphology. In addition, we could not evaluate the structural alterations of small resistance arteries at cellular levels (vascular smooth muscle cell hypertrophy or hyperplasia), because of the complexity of the techniques needed. ${ }^{32}$

In conclusion, the MHS presents cardiac (but not vascular) remodeling, endothelial dysfunction and a peculiar contractile response to NE, compared with the other groups. The increase in systolic blood pressure, together with the observed trend to vascular remodeling observed in the MNA strain support a pathogenic role of $\alpha$-adducin. The nature of the mechanisms underlying the endothelial dysfunction and enhanced contractility to NE in the MHS needs to be further elucidated.

\section{CONFLICT OF INTEREST}

The authors declare no conflict of interest.

1 Staessen JA, Bianchi G. Adducin and hypertension. Pharmacogenomics 2005; 6: 665-669.

2 Bianchi G, Ferrari P, Staessen JA. Adducin polymorphism. Detection and impact on hypertension and related disorders. Hypertension 2005; 45: 331-340. 
3 Castellano M, Barlassina C, Muiesan ML, Beschi M, Cinelli A, Rossi F, Rizzoni D, Cusi D, Agabiti-Rosei E. Alpha-adducin gene polymorphism and cardiovascular phenotypes in a general population. J Hypertens 1997; 15 (12 Part 2): 1707-1710.

4 Sarzani R, Cusi D, Salvi F, Barlassina C, Macciardi F, Pietrucci F, Cola G, Catalini R, Dal Fiume C, Dessì-Fulgheri P, Rappelli A. The 460Trp allele of alpha-adducin increases carotid intima-media thickness in young adult males. J Hypertens 2006; 24: 697-703.

5 Balkestein EJ, Wang JG, Struijker-Boudier HA, Barlassina C, Bianchi G, Birkenhäger WH, Brand E, Den Hond E, Fagard R, Herrmann SM, Van Bortel LM, Staessen JA. Carotid and femoral intima-media thickness in relation to three candidate genes in a Caucasian population. J Hypertens 2002; 20: 1551-1561.

6 Balkestein EJ, Staessen JA, Wang JG, van Der Heijden-Spek JJ, Van Bortel LM, Barlassina C, Bianchi G, Brand E, Herrmann SM, Struijker-Boudier HA. Carotid and femoral artery stiffness in relation to three candidate genes in a White population. Hypertension 2001; 38: 1190-1197.

7 Laurent S. Genotype interactions and intima-media thickness. J Hypertens 2002; 20 : 1477-1478.

8 Perticone F, Sciacqua A, Barlassina C, Del Vecchio L, Signorello MC, Dal Fiume C, Andreozzi F, Sesti G, Cusi D. Gly460Trp alpha-adducin gene polymorphism and endothelial function in untreated hypertensive patients. J Hypertens 2007; 25: 2234-2239.

9 Tripodi G, Florio M, Ferrandi M, Modica R, Zimdahl H, Hubner N, Ferrari P, Bianchi G. Effect of Add1 gene transfer on blood pressure in reciprocal congenic strains of Milan rat. Biochem Biophys Res Commun 2004; 324: 562-568.

10 Mulvany MJ, Halpern W. Contractile properties of small resistance vessels in spontaneously hypertensive and normotensive rats. Circ Res 1977; 41: 19-26.

11 Mulvany MJ, Hansen PK, Aalkjaer C. Direct evidence that the greater contractility of resistance vessels in spontaneously hypertensive rats is associated with a narrowed lumen, a thickened media, and an increased number of smooth muscle cell layers. Circ Res 1978; 43: 854-864.

12 Rizzoni D, Castellano M, Porteri E, Bettoni G, Muiesan ML, Agabiti-Rosei E. Vascular structural and functional alterations before and after the development of hypertension in SHR. Am J Hypertens 1994; 7: 193-200.

13 Rizzoni D, Castellano M, Porteri E, Bettoni G, Muiesan ML, Agabiti Rosei E. Delayed development of hypertension after short-term nitrendipine treatment. Hypertension 1994; 24: 131-139.

14 Rizzoni D, Porteri E, Piccoli A, Castellano M, Bettoni G, Muiesan ML, Pasini G, Guelfi D, Mulvany MJ. Agabiti Rosei Effects of losartan and enalapril on small artery structure in hypertensive rats. Hypertension 1998; 32: 305-310.

15 Vecchione C, Frata L, Rizzoni D, Notte A, Poulet R, Porteri E, Frati G, Guelfi D, Trimarco V, Mulvany MJ, Agabiti Rosei E, Trimarco B, Cotecchia S, Lembo G. Cardiovascular influences of $\alpha_{1 \mathrm{~B}}$-adrenergic receptor in mice. Circulation 2002; 105: 1700-1707.

16 Ferrari P, Ferrandi M, Valentini G, Manunta P, Bianchi G. Targeting ouabain and adducin-dependent mechanism of hypertension and cardiovascular remodeling as a novel pharmacological approach. Med Hypotheses 2007; 68: 1207-1314.

17 Ferrari P, Ferrandi M, Valentini G, Bianchi G. Rostafuroxin: an ouabain antagonist that corrects renal and vascular Na+-K+- ATPase alterations in ouabain and adducin- dependent hypertension. Am J Physiol Regul Integr Comp Physiol 2006; 290: R529-R535. Review.

18 Je HD, Gallant C, Leavis PC, Morgan KG. Caveolin-1 regulates contractility in differentiated vascular smooth muscle. Am J Physiol Heart Circ Physiol 2004; 286: H91-H98.

19 Forte A, Esposito S, De Feo M, Galderisi U, Quarto C, Esposito F, Renzulli A, Berrino L, Cipollaro M, Agozzino L, Cotrufo M, Rossi F, Cascino A. Stenosis progression after surgical injury in Milan hypertensive rat carotid arteries. Cardiovasc Res 2003; 60: 654-663.

20 Morishige K, Shimokawa H, Eto Y, Kandabashi T, Miyata K, Matsumoto Y, Hoshijima M, Kaibuchi K, Takeshita A. Adenovirus-mediated transfer of dominant-negative Rhokinase induces a regression of coronary arteriosclerosis in pigs in vivo. Arterioscler Thromb Vasc Biol 2001; 21: 548-554.

21 Mulvany MJ, Aalkjaer C. Structure and function of small arteries. Physiol Rev 1990; 70: 921-971.

22 Heagerty AM, Aalkjaaer C, Bund SJ, Korsgaard N, Mulvany MJ. Small artery structure in hypertension. Dual process of remodeling and growth. Hypertension 1993; 21: 391-397.

23 De Ciuceis C, Rizzoni D, Agabiti Rosei C, Porteri E, Boari GEM, Agabiti Rosei E. Remodelling of small resistance arteries in essential hypertension. High Blood Press 2006; 13: 1-6.

24 Mulvany MJ, Persson AE, Andresen J. No persistent effect of angiotensin converting enzyme inhibitor treatment in Milan hypertensive rats despite regression of vascular structure. J Hypertens 1991; 9: 589-593.

25 Rizzoni D, Castellano M, Porteri E, Bettoni G, Muiesan ML, Cinelli A, Zulli R, AgabitiRosei E. Prolonged effects of short-term fosinopril on blood pressure and vascular morphology and function in rats. Am J Hypertens 1997; 10: 1034-1043.

26 Rizzoni D, Castellano M, Porteri E, Bettoni G, Muiesan ML, Cinelli A, Agabiti Rosei E. Effects of low and high doses of fosinopril on the structure and function of resistance arteries. Hypertension 1995; 26: 118-123.

27 Mulvany MJ. Small artery remodeling and significance in the development of hypertension. News Physiol Sci 2002; 17: 105-109.

28 Cooper IV G. Basic determinants of myocardial hypertrophy: a review of molecular mechanisms. Annu Rev Med 1997; 48: 13-23.

29 Barlassina C, Perticone F, Gelfi C, Dal Fiume C, Ruello A, Sciacqua A. The 460Trp allele of Add1 activates ROS production and causes endothelial dysfunction in essential hypertension. J Hypertens 2005; 23 (Suppl 2): S263 (abstract).

30 Tripodi G, Valtorta F, Torielli L, Chieregatti E, Salardi S, Trusolino L. Hypertensionassociated point mutations in the adducin alpha and beta subunits affect actin cytoskeleton and ion transport. J Clin Invest 1996; 97: 2815-2822.

31 Tripodi MG, Valtorta F, Torielli L, Chieregatti E, Salardi S, Trusolino L, Menegon A, Ferrari P, Marchisio PC, Bianchi G. Hypertension associated point mutations in the adducin $\alpha$ and $\beta$ subunits affect actin cytoskeleton and ion transport. $J$ Clin Invest 1996; 97: 2815-2822.

32 Rizzoni D, Porteri E, Guelfi D, Piccoli A, Castellano M, Pasini G, Muiesan ML, Mulvany MJ, Agabiti Rosei E. Cellular hypertrophy in subcutaneous small arteries of patients with renovascular hypertension. Hypertension 2000; 35: 931-935. 